\title{
General Psychiatry A case of neurosyphilis with psychosis and hippocampal atrophy
}

\author{
Mohammed Murtza, ${ }^{1}$ Ayesha Bangash (D) ,2 Ajaz-Ur Rehman, ${ }^{1}$ Amjadali Pervaiz, ${ }^{1}$ \\ Adeena Imran ${ }^{1}$
}

To cite: Murtza M, Bangash $A$, Rehman A-U, et al. A case of neurosyphilis with psychosis and hippocampal atrophy. General Psychiatry 2022;35:e100674. doi:10.1136/ gpsych-2021-100674

Received 24 September 2021 Accepted 16 February 2022
Check for updates

(c) Author(s) (or their employer(s)) 2022. Re-use permitted under CC BY-NC. No commercial re-use. See rights and permissions. Published by BMJ.

${ }^{1}$ General Psychiatry, South West Yorkshire Partnership NHS Foundation Trust, Halifax, UK ${ }^{2}$ Old Age Psychiatry, South West Yorkshire Partnership NHS Foundation Trust, Halifax, UK

Correspondence to Dr Ayesha Bangash; 520ayesha@gmail.com

\section{ABSTRACT}

Neurosyphilis can mimic many neurological and psychiatric disorders. Though several of its varied central nervous system manifestations can be measured clinically and by neuroimaging, they are non-specific. Thus, this mimicry and the relative rarity of the illness in the present era make the diagnosis elusive. However, neurosyphilis is readily treatable; therefore, it must be considered a diagnostic possibility in the routine workup of early-onset dementia. This case report is of a young man presenting with psychosis and cognitive impairment. His brain scan showed hippocampal atrophy, a finding not often seen in neurosyphilis but more common in Alzheimer's disease. Without awareness of the various causes of mesiotemporal atrophy, clinicians may erroneously diagnose cases such as this one as a neurodegenerative disorder.

\section{INTRODUCTION}

Syphilis, caused by the bacterium Treponema pallidum, is often named 'the great imitator' in the literature due to its ability to mimic other conditions. ${ }^{1}$ Neurosyphilis, a complicated bacterial infection of the brain or spinal cord, is uncommon today, unlike during the era before the introduction of penicillin. ${ }^{2}$ Only $5 \%-10 \%$ of those infected with syphilis develop this central nervous system comorbidity, and of these, one-third exhibit clinical signs of the disorder. In addition, neurosyphilis may develop during any stage after the initial exposure to syphilis, often manifesting years or even decades later. However, the low incidence with syphilis infection suggests that spontaneous healing is possible. ${ }^{3}$ Early neurosyphilis can present as meningitis, meningovascular syphilis or asymptomatic neurosyphilis. Late neurosyphilis can appear as paretic neurosyphilis (general paresis), dementia and tabes dorsalis characterised by sensory ataxia, peripheral neuropathy and cranial nerve lesions. Movement disorders, although rare, can also occur. ${ }^{4}$ In addition, psychiatric symptoms such as mood changes (including depression and mania), hallucinations, delusions, personality changes, cognitive impairment, delirium and dementia can develop, though more commonly in the early stages of neurosyphilis. Nonetheless, patients with neurosyphilis can also be asymptomatic. ${ }^{1}$ We describe the case of a young man who experienced psychosis and hippocampal atrophy associated with cognitive impairment as part of a neurosyphilis presentation.

\section{CASE REPORT}

A Slovakian man in his 30s was admitted to an acute psychiatry ward. Because his spoken English was limited, his family members and an interpreter assisted the inpatient team in gathering relevant information about the patient's history.

The patient had had an uncomplicated vaginal delivery at birth and normal childhood development. Up to the age of 15 years, he had performed well in school. But then he started playing truant to spend time with others who used illicit substances. He later failed to obtain any graduation qualifications and never could hold down a steady job. He had a girlfriend for a brief period during his 20s but no other relationships or sexual encounters. The patient had no children. Though he had no history of alcohol use, he began using cannabis at 15 years of age. He moved to the UK during his early 20 s and continued to use cannabis until he was 25 years old. His urine drug screen was negative on admission.

The family reported that he had been a social, caring person with no impaired functional ability, but his overall demeanour changed after moving to the UK. Gradually, he became devoid of feeling and showed little care for others. He secluded himself in his room while continuously watching television and laughing at murder scenes. Eventually, his family had to assist with his activities of daily living because of his short-term memory loss and increasingly impaired functional ability. Earlier, when he had attempted to find a job, he was advised first to learn English. After going to college classes a few times, 
he stopped attending because he struggled to retain the content of the lessons.

A few months before hospital admission, as his family was struggling to cope with his deterioration, he was referred by his general practitioner to the community mental health team. He was observed talking to unseen stimuli, and his long-term memory showed evidence of decline. He became incontinent of urine-sometimes unaware of this-and his body odour was malodorous. In addition, he lost weight as he believed that his family was poisoning his food. Because of his inability to care for himself, his family could not leave him unattended for long periods. He became terrified of leaving his home alone due to fear of being watched by others. At times he became agitated and irritable. At one point, he even threatened his family with a knife. Another time he threw a computer out the window, which damaged a neighbour's car.

The patient's engagement with staff and peers was minimal on the psychiatric ward. He preferred spending long periods in his bedroom and only exited with staff's encouragement. There were no abnormal findings on physical examination. During the day, he slept for long periods, but he paced the ward at night. His responses to questions were minimal and monosyllabic. The initiation of risperidone showed a slight improvement in his psychosis.

Various clinical investigations were arranged to ascertain the cause of his cognitive decline. The Rowland Universal Dementia Assessment Scale (RUDAS) was selected as it is designed to minimise the effects of cultural learning and language diversity when assessing baseline cognitive performance. The patient's score was 8 (30 in total), with points lost in the memory, visuospatial, judgement and language domains. Computed tomography (CT) scan of the brain showed medial temporal atrophy with a prominence of the temporal horns of the lateral ventricles (figure 1). Magnetic resonance imaging (MRI) scan of the brain demonstrated bilateral hippocampal atrophy, an abnormality for someone of his age. Also, generalised mild cortical atrophy of the brain was found. His full

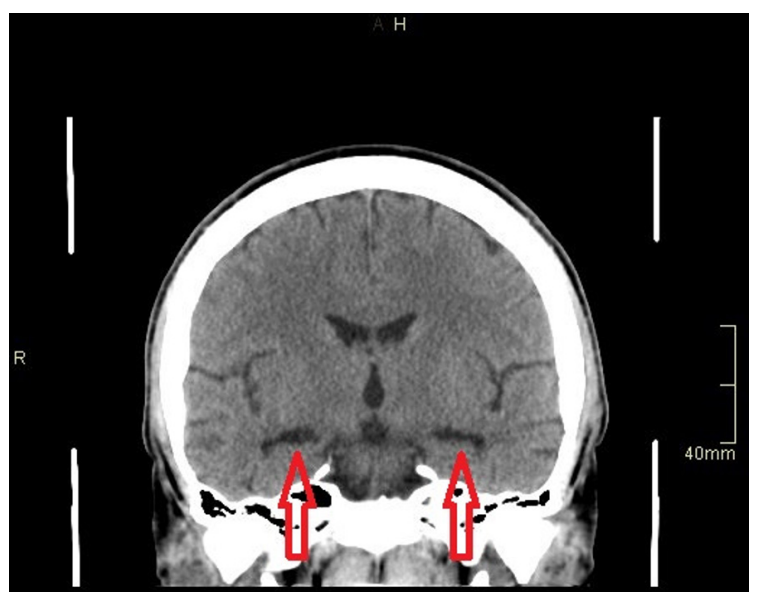

Figure 1 Arrows showing medial temporal atrophy. blood count, liver function tests, bone profile, lupus anticoagulant screen, encephalitis screen and thyroid function tests were normal. Serum levels of folate, vitamin $B_{12}$, urea and electrolytes, copper, lead, manganese, mercury, angiotensin converting enzyme (ACE), rheumatoid factor and caeruloplasmin were also normal. Human immunodeficiency virus (HIV) and hepatitis B serology were normal. PCR tests for Chlamydia trachomatis and Neisseria gonorrhoeae were negative. Neuronal, voltage-gated potassium channel, N-methyl-D-aspartate receptor and antinuclear antibody testing were negative. Regarding tests for syphilis, the T. pallidum particle agglutination (TPPA) assay (1:>20 480), rapid plasma reagin (RPR) test (1:256) and IgM antibody assay were positive.

The patient was then reviewed by the genitourinary medicine (GUM) team for a suspected diagnosis of neurosyphilis. Cerebrospinal fluid (CSF) analysis showed normal white cells, red cells, proteins and glucose. No organisms were seen. CSF TPPA titre was 1:640; however, RPR was not detected. He was given a course of procaine penicillin 12.4 million units intramuscularly daily and probenecid $500 \mathrm{mg}$ orally four times per day for 14 days. Three days prior to starting antibiotics, he was given prednisolone $40 \mathrm{mg}$ daily for 3 days. Within the first few weeks of treatment, he became more communicative with his family and interested in his appearance. His paranoia decreased, and there were no reports of responding to unseen stimuli. One month after the initial assessment, his RUDAS score had increased to 15 (30 in total), with points again lost in the domains mentioned above. A repeat RPR titre after 3 months was 1:32. Based on the improved syphilis test results, changed MRI findings and decreased psychiatric symptoms with treatment, the GUM team concluded that he had a diagnosis of neurosyphilis.

\section{DISCUSSION}

There are no gold standard diagnostic tests for neurosyphilis. Moreover, there is no consensus regarding diagnostic criteria. Clinical suspicion plays a major role in making a diagnosis. CSF analysis with non-treponemal tests such as the Venereal Disease Research Laboratory (VDRL) test or RPR is recommended. However, CSF non-treponemal tests are not particularly sensitive and do not eliminate the possibility of neurosyphilis in the case of negative results. CSF treponemal tests such as TPPA are more contrastingly specific but less sensitive, so they do not confirm the diagnosis but help to exclude it. Increased protein and leucocyte levels do not particularly help confirm a diagnosis, but if there is no change over time, they can reduce the chances of having neurosyphilis. ${ }^{5}$ Elevated CSF protein can be a non-specific parameter. In the early phase of syphilis, IgM antibodies are detected. The sensitivity of a positive $T$. pallidum-specific antibody test is generally high; however, it may not explain the disease activity since antibodies can persist for life after treatment or with the spontaneous 
healing of syphilis. Coinfections with HIV, chlamydia, gonococci, hepatitis B and hepatitis C can occur, so they should be ruled out. ${ }^{3}$

The patient was given parenteral procaine penicillin, oral probenecid and steroids. Alternative antibiotic regimes that can be given include benzylpenicillin $1.8-2.4 \mathrm{~g}$ intravenously every 4 hours for 14 days, doxycycline $200 \mathrm{mg}$ orally two times per day for 28 days, amoxicillin $2 \mathrm{~g}$ orally three times per day for 28 days and ceftriaxone $2 \mathrm{~g}$ via the parenteral route for 10-14 days. Steroids should be given with all anti-treponemal antibiotics for neurosyphilis. Follow-up blood tests are generally performed at 3, 6, 12, 24 and 36 months to ensure the infection has gone. ${ }^{6}$

Untreated neurosyphilis can result in devastating neurological sequelae, including permanent paralysis, dementia and death. ${ }^{4}$ Hippocampal atrophy can occur in neurosyphilis but is not commonly seen. Some case reports of this have been mentioned in the literature. ${ }^{7-14}$ Hippocampal atrophy can contribute to a dementia diagnosis as it is seen more commonly in Alzheimer's disease ${ }^{15}$; therefore, it is essential to rule out neurosyphilis in younger patients. Furthermore, mesiotemporal atrophy can be seen in herpes simplex encephalitis or paraneoplastic limbic encephalitis. ${ }^{16}$

The effect of cannabis on the patient's presentation was considered as it can cause psychosis. ${ }^{17}$ It can bring about cognitive impairment and alterations in the hippocampus. ${ }^{18} 19$ The patient used cannabis from the age of 15 to 25 years. Despite not using cannabis during his 30s, when he became known to the mental health service, his cognition did not improve. The effects of cannabis on memory and performance usually fade with abstinence. ${ }^{20}$ It is possible that he became infected with syphilis at the time of a sexual relationship during his 20s. Cannabis use may have impacted his cognition and educational performance earlier in his life, but most probably did not impact the difficulties he experienced beyond his late 20s.

As seen in our patient, personality changes are associated with late syphilis, indicating that the disease has been present for a long time. ${ }^{1} \mathrm{Up}$ to $20 \%$ of cases can present with primary psychiatric symptoms, which often delays finding the actual diagnosis and required treatment. Neurosyphilis should be considered in young patients who demonstrate a poor response to antipsychotics. ${ }^{21}$

\section{CONCLUSION}

Neurosyphilis is an uncommon condition; however, it is the most debilitating and life-altering outcome of untreated syphilis infection. Fortunately, the prognosis of neurosyphilis has improved significantly in recent decades due to rapid and adequate antibiotic treatment. ${ }^{3}$ It is crucial for clinicians to diagnose and treat those affected with neurosyphilis because of the potentially irreversible complications it can cause. In addition, the scientific community should create diagnostic criteria and tools that are universally acceptable.
Contributors MM drafted the case report and manuscript. A-UR and Al performed the literature search. AB and AP supervised and revised the manuscript. All authors approved the final manuscript.

Funding The authors have not declared a specific grant for this research from any funding agency in the public, commercial or not-for-profit sectors.

Competing interests None declared.

Patient consent for publication Obtained.

Ethics approval This study does not involve human participants.

Provenance and peer review Not commissioned; externally peer reviewed.

Open access This is an open access article distributed in accordance with the Creative Commons Attribution Non Commercial (CC BY-NC 4.0) license, which permits others to distribute, remix, adapt, build upon this work non-commercially, and license their derivative works on different terms, provided the original work is properly cited, appropriate credit is given, any changes made indicated, and the use is non-commercial. See: http://creativecommons.org/licenses/by-nc/4.0/.

ORCID iD

Ayesha Bangash http://orcid.org/0000-0003-2912-7614

\section{REFERENCES}

1 Saini HS, Sayre M, Saini I, et al. Neurosyphilis presenting as intermittent explosive disorder and acute psychosis. Cureus 2019;11:e6337.

2 Landeiro L, Oliveira R, Graça J, et al. Traditional neurosyphilis in 21st Century - tabes dorsalis, dementia paralytica, aseptic meningitis and unilateral oculomotor nerve palsy in an HIV-negative man. Cureus 2021;13:e18869.

3 Klein M, Angstwurm K, Esser S, et al. German guidelines on the diagnosis and treatment of neurosyphilis. Neurol Res Pract 2020;2:33.

$4 \mathrm{Ha} \mathrm{T}$, Tadi P, Dubensky L. Neurosyphilis. In: StatPearls. Treasure Island (FL): StatPearls Publishing, 2021. https://www.ncbi.nlm.nih. gov/books/NBK540979/

5 Boog GHP, Lopes JVZ, Mahler JV, et al. Diagnostic tools for neurosyphilis: a systematic review. BMC Infect Dis 2021;21:568.

6 British Association for Sexual Health and HIV (BASHH). Syphilis. Lichfield, UK: BASHH, 2015. https://www.bashhguidelines.org/ current-guidelines/genital-ulceration/syphilis-2015/

7 Jeong YM, Hwang HY, Kim HS. Mri of neurosyphilis presenting as mesiotemporal abnormalities: a case report. Korean J Radiol 2009;10:310-2.

8 Mehrabian S, Raycheva M, Traykova M, et al. Neurosyphilis with dementia and bilateral hippocampal atrophy on brain magnetic resonance imaging. BMC Neurol 2012;12:96.

9 Tombor L, Salacz P, Jankelovics Éva, et al. [Four-year follow-up of a neurosyphilis case presenting psychiatric symptoms]. Orv Hetil 2018;159:234-8.

10 Zifko $\mathrm{U}$, Wimberger D, Lindner K, et al. MRI in patients with general paresis. Neuroradiology 1996;38:120-3.

11 Van Eijsden P, Veldink JH, Linn FH, et al. Progressive dementia and mesiotemporal atrophy on brain MRI: Neurosyphilis mimicking presenile Alzheimer's disease? Eur J Neurol 2008;15:e14-15.

12 Chen C-W, Chiang H-C, Chen P-L, et al. General paresis with reversible mesial temporal T2-weighted hyperintensity on magnetic resonance image: a case report. Acta Neurol Taiwan 2005;14:208-12.

13 Fujimoto H, Imaizumi T, Nishimura Y, et al. Neurosyphilis showing transient global amnesia-like attacks and magnetic resonance imaging abnormalities mainly in the limbic system. Intern Med 2001;40:439-42.

14 Marano E, Briganti F, Tortora F, et al. Neurosyphilis with complex partial status epilepticus and mesiotemporal MRI abnormalities mimicking herpes simplex encephalitis. J Neurol Neurosurg Psychiatry 2004;75:833.

15 Maclin JMA, Wang T, Xiao S. Biomarkers for the diagnosis of Alzheimer's disease, dementia Lewy body, frontotemporal dementia and vascular dementia. Gen Psychiatr 2019;32:e100054.

16 Dekeyzer S, De Kock I, Nikoubashman O, et al. "Unforgettable" - a pictorial essay on anatomy and pathology of the hippocampus. Insights Imaging 2017;8:199-212.

17 Mellsop G, Tapsell R, Holmes P. Mental health service users' progression from illicit drug use to schizophrenia in New Zealand. Gen Psychiatr 2019;32:e100088. 
18 Dhein S. Different effects of cannabis abuse on adolescent and adult brain. Pharmacology 2020;105:609-17.

19 Archie SR, Cucullo L. Harmful effects of smoking cannabis: a cerebrovascular and neurological perspective. Front Pharmacol 2019;10:1481.
20 Bruijnen CJWH, Dijkstra BAG, Walvoort SJW, et al. Prevalence of cognitive impairment in patients with substance use disorder. Drug Alcohol Rev 2019;38:435-42.

21 Nutile LM. Neurosyphilis with psychosis as the primary presentation. Am J Psychiatry Resid J 2021;16:6-8.

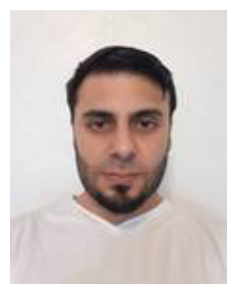

Mohammed Murtza is a first-year core psychiatry trainee at South West Yorkshire Partnership NHS Foundation Trust in the UK. He has a Postgraduate Certificate in Education (PGCE) and qualified teacher status (QTS). He has also completed a Master of Science (MSc) and a Bachelor of Science (BSc) Honours in medicinal chemistry. He received his $M B C h B$ from the University of Leeds and is currently working on an acute inpatient psychiatric unit, focusing on working-aged individuals. His main research interests include neuropsychiatry and psychopharmacology. 